\title{
Proliferating Cells in Knee Epiphyses of Lizards Allow for Somatic Growth and Regeneration after Damage
}

\author{
Lorenzo Alibardi \\ Comparative Histolab and Department of Biology, University of Bologna, via Selmi 3, 40126, Bologna, Italy; \\ lorenzo.alibardi@unibo.it; Tel.: +39-051-209-4142
}

Received: 28 April 2017; Accepted: 5 July 2017; Published: 7 July 2017

\begin{abstract}
After bone damage, fracture or amputation, lizards regenerate a variable mass of cartilaginous and fibro-cartilaginous tissues, depending from the anatomical site and intensity of inflammation. Aside tail and vertebrae, also long bones and knee epiphyses can regenerate a relative large mass of cartilage after injury. Regeneration is likely related to the persistence of stem cells in growing centers of these bones, localized in the epiphyses of femur, tibia and fibula. The epiphyses form ossified secondary centers in adults but a few progenitor cells remain in the articular cartilage and growth plate, allowing a continuous growth during most lifetime of lizards. The present Review indicates that putative progenitor/stem cells, identified by long labeling retaining of 5-bromo-deoxy-uridine (5BrdU) and immunolocalization of telomerase, remain localized in the articular cartilage and growth plates of the femur and tibia. These cells are re-activated after limited epiphyses damage or amputation of the distal part of the femur or tibia-fibula, and can re-form cartilaginous epiphyses. Regenerating chondrocytes show an intense proliferation and the production of new extracellular matrix components such as collagen VI, chondroitin sulfate proteoglycan, and hyaluronate receptors. The molecular factors at the origin of the chondrogenic potential of the articular cartilage, growth plates, and the periosteum in lizard bones remain to be studied.
\end{abstract}

Keywords: lizard; knee epiphyses; cartilage regeneration; microscopy

\section{Introduction}

Lizards are capable of massive cartilage regeneration, mainly in the regenerating tail where a long cartilaginous tube substitutes for the original vertebral column [1-10]. However, also fractured femurs [11] and injured knees of adult lizards [12,13] have shown a broad cartilaginous regeneration, suggesting that these ectothermic amniotes are an important model for studies on cartilage regeneration in vertebrates $[9,10,14]$.

Regeneration of cartilaginous cells in injured bones and knees of lizards is a remarkable case of cartilage regeneration in amniotes, in comparison to the limited cartilage regeneration detected in mammals [11-20]. In the latter, the injured periosteum gives rise to a fibro-connective tissue and to some new chondrocytes. Later, new bone derives from endosteum and bone marrow, which give rise to osteoblasts that directly ossify forming lamellar bone [19]. Even more pronounced in amphibians than in lizards, the cartilaginous tissue can regenerate more abundantly following bone fracture or some injuries in the epiphyses $[11,20,21]$. However large injuries or the complete removal of the epiphyses also in newts often determines lack of regeneration, an unexpected result considering the broad regeneration of a complete limb with the knee or elbow in these amphibians after limb amputation [21,22]. 
Like during limb regeneration, also the regeneration of the knee in amniotes can be linked to the degree of inflammation produced after a natural traumatic or an experimental intervention, so that a strong immune reaction can adversely affect the entire process of recovery [23-25].

In the present Review we summarize previous studies conducted on an amniote model of cartilage regeneration, the lizard. The Review initially presents the stages where the knee is formed in the embryo and moves to juvenile and adult stages, where the knee is fully ossified with the formation of secondary centers of ossification. The presentation shows that the cartilaginous tissues contains sparse progenitor/stem cells and slow proliferating cells, which localization in the epiphyses derives from the embryonic morphogenesis of the bones, and generally these cells allow the continuous skeletal growth in lizards. It is indicated that these putative progenitor cells give rise to the new, regenerated cartilage after un-direct or direct damage such as amputation of the limb or direct knee injury, providing the damage is not excessive. The Review introduces to the following study on the massive regeneration of cartilaginous tissue that forms the cartilaginous anlagen of a new femur, tibia and fibula in the amputated hindlimb of lizards after stimulation with Fibroblast Growth Factor FGF1-2 ([26], this volume).

\section{Knee Formation and Maturation}

Embryos of the iguanid lizard Anolis lineatopus at progressive stages of development, juveniles at estimated age of 1-2 years and adults of Podarcis muralis at estimated age of at least 3-4 years, by their size, were here utilized and fixed for the study of knee development and maturation as previously indicated [27]. Embryos of A. lineatopus at stage 34, when the limb and fingers are incompletely separated, to stage 38 when fingers are fully separated and claws are almost completed at few days before hatching, were utilized. As previously reported, the embryos were injected with 5-bromo-deoxy-uridine (5BrdU) and fixed at 1, 2 and 4 days post-injection, and the sectioned limbs with the forming knees were studied for $5 \mathrm{BrdU}$ immunohistochemistry in order to visualize the sites of localization of proliferating cells.

Results from these studies showed that the forming knees in embryos of $A$. lineatopus at stages $34-37$, the cartilaginous femur and tibia at 1 to 4 days post-injection of $5 \mathrm{BrdU}$, show proliferating cells mainly localized at the epiphyses of the cartilaginous anlagen of the femur and tibia that appear separated one from another, while rare cells are seen in the diaphyses (Figure 1A). The forming articular surfaces of the femur and tibia also show sparse labeled cells and the localization of 5BrdU-labeled cells is also maintained in juvenile epiphyses. The typical epiphyses shape at the two sides of the femur and tibia likely derives from the increase in the number of proliferating cells in these areas in comparison to the diaphysis, where chondrocytes instead differentiate. Similar observations are also reported for mammalian long bones [28-30]. The formation of the metaphysis or growth plate begins at stage 34 when chondroblasts in this region pile up and assume a flat shape. The initial ossification by lamellar bone deposition in the diaphysis initiates at embryonic stage 35 (fingers completely separated). Chondrocytes in the diaphysis are largely replaced by spongy bone after embryonic stage 36, near hatching, but the epiphyses remain cartilaginous.

The study on normal knees and on knees injured in juveniles and adults of Podarcis muralis was conducted as previously reported (see details in $[12,13]$ ). Briefly, the knee was injured using the tips of fine scissors to produce 3-4 cuts of the articular surface of the epiphysis in the femur and tibia of knees. After 21 and 32 days post-lesion, the animals were injected with 5BrdU 4 hours before sacrifice, and the injured knees were collected, examined histologically and by immunohistochemistry for $5 \mathrm{BrdU}$ detection. Also the immune-detection of three cartilage markers such as Chondroitin Sulphate Proteoglycan, Hyaluronate Receptor (mouse MAB 1970, Chemicon, Rolling Meadows, IL, USA) and Collagen VI (Mouse ab, Hybridoma Bank, Iowa City, IA, USA) was carried out (details in [12,13]).

The epiphyses of juvenile lizards of the lizard Podarcis muralis are still mainly cartilaginous and small secondary ossification centers are seen in the femur and occasionally in the tibia, but not in the fibula (Figure 1B). Adult knees in both P. muralis and A. carolinensis instead feature secondary 
centers in the femur and tibia, while a rim of cartilaginous tissues remains to form the articular surface of the femur and large areas of the tibia and fibula (Figure 1C,D). Variably shaped secondary ossification centers are present inside the epiphyses of adult lizards [31,32], and a variable number of 5BrdU-labeled cells remain in these areas as well as along the articular cartilage and the growth plate. This localization of labeled cells was noted in the femur and tibia of both juveniles and adult lizards (Figure 2A-D). Therefore cartilaginous cell progenitors remain in the epiphyses of the knees in lizards for most of their life, and these cells likely sustain the slow but continuous growth of these amniotes, a possible pre-adaptation to cartilage regeneration in case of knee injury.
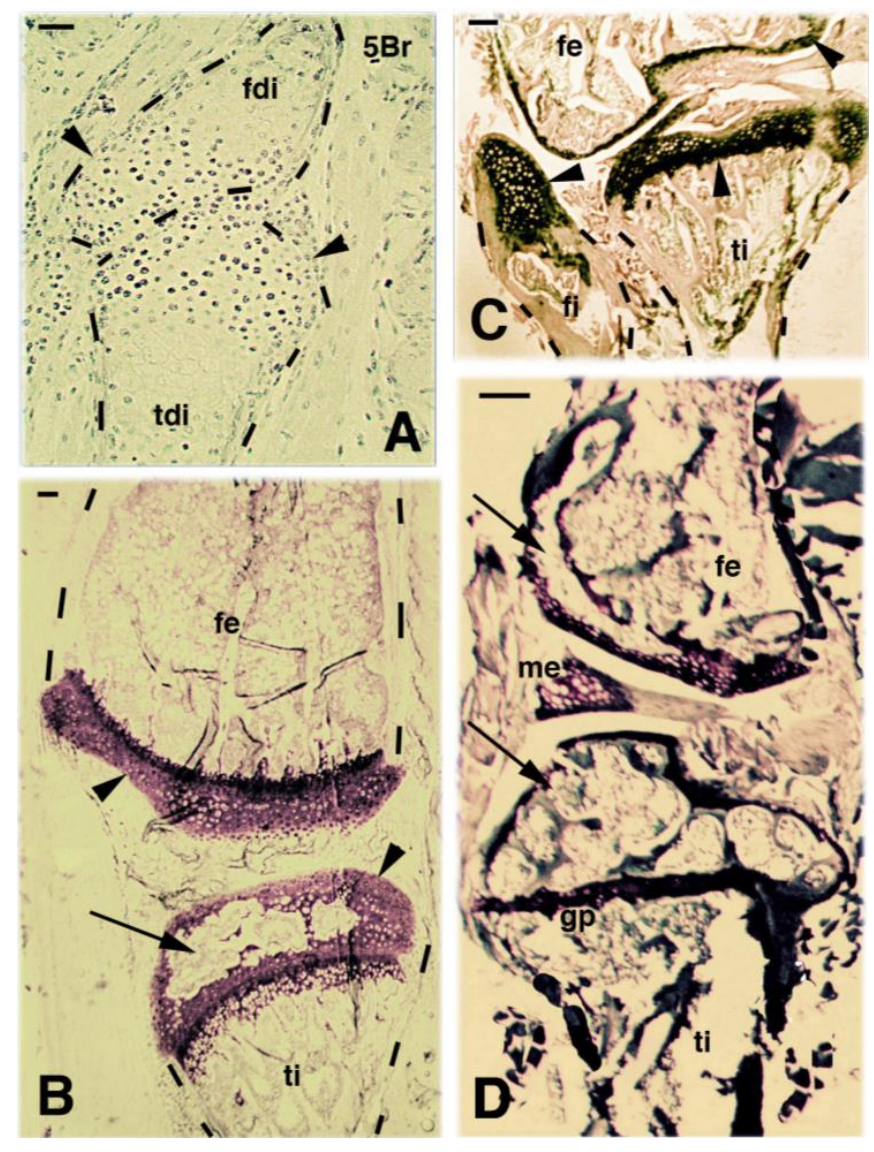

Figure 1. Microscopic images of developing (A, Light toluidine blue stain.), juvenile (B, toluidine blue stain), and adult (C,D), Methylene blue-Eosin stain) knee. (A) immunostaining for 5-bromo-deoxy-uridine (5BrdU) (5Br, 2 days post-injection) showing labeled cells (dark spots) located mainly in the epiphyses (arrowheads) of developing femur and tibia at stage 35 in Anolis lineatopus. Bar, $20 \mu \mathrm{m}$; (B) juvenile knee showing the still developed articular cartilages (arrowheads) in Podarcis muralis. The initial formation of a secondary ossification center (arrow) is seen in the tibia. Bar, $20 \mu \mathrm{m}$; (C) reduction of the articular cartilage in this part of the femur while a larger cartilage is seen in the tibia and the narrow fibula epiphysis (arrowheads) in P. muralis. Bar, $50 \mu \mathrm{m}$; (D) most of the tibia and femur epiphyses is occupied by ossification centers (arrows) and little cartilage remains in adults of P. muralis. Bar, $100 \mu \mathrm{m}$. Legends: fdi, femur diaphysis (differentiating); fe, femur; fi, fibula; me, meniscus; gp, growth plate (metaphyseal plate); tdi, tibia diaphysis (forming); ti, tibia; The dashes outline the bone shape.

It should be noted however that the experiments so far conducted on normal (non injured) knees have not verified whether the injury of the contra-lateral knee can also affect the proliferative activity of the non-injured, normal knee. This hypothetic, indirect influence may derive from the production of diffusible factors carried through the blood to the contralateral, uninjured knee or simply by increasing 
the mechanical load on the normal knee to support the contralateral, impaired knee. Therefore the variable proliferative activity of the normal knee, due to individual variations or related to different ages, or somehow affected by the contra-lateral lesion, requires a further analysis before a definitive conclusion on cell proliferation in normal knees can be drawn.
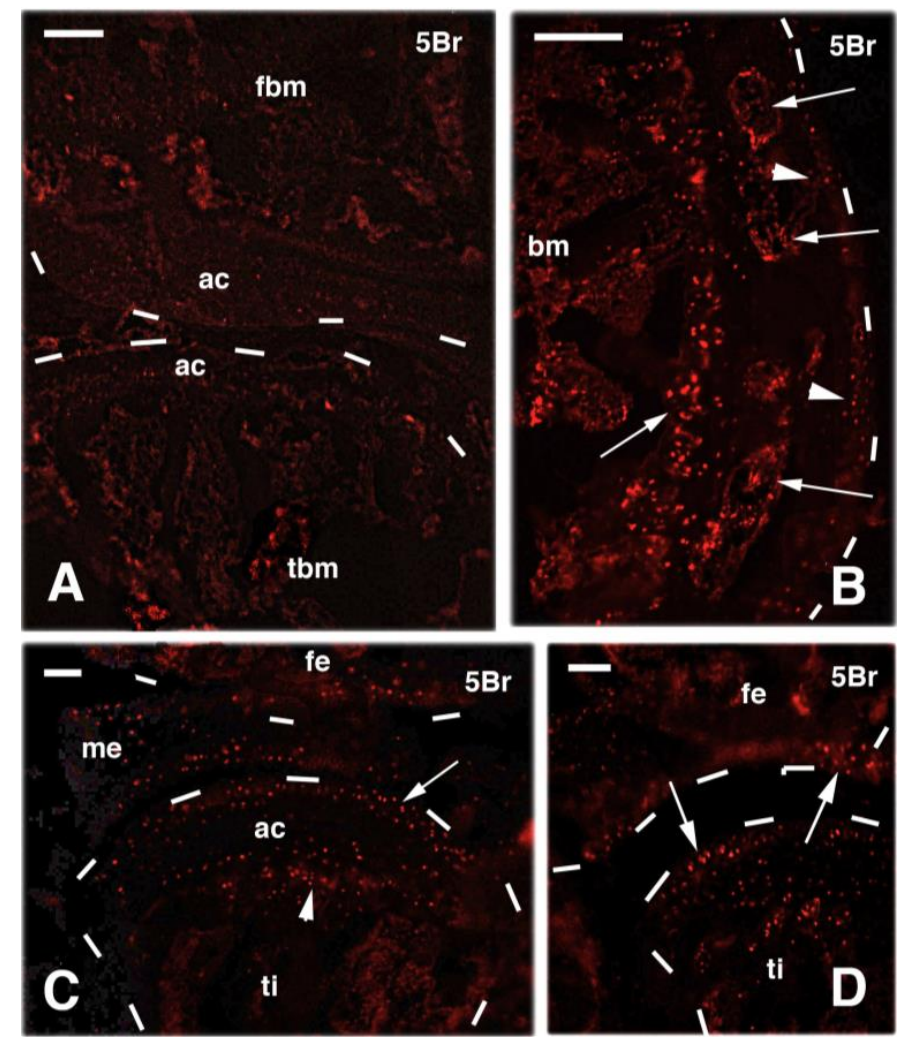

Figure 2. TRITC immunofluorescence (red) of normal knees $4 \mathrm{~h}$ after injection of 5BrdU. (A) both femur (top) and tibia (bottom) epiphyses contain very few labeled cells (red dots) in this case. Bar, $50 \mu \mathrm{m}$; (B) detail on another case of normal knee showing more numerous labeled cells in both the articular cartilage surface (arrowheads) and within secondary centers of ossification in the epiphysis (arrows). Bar, $25 \mu \mathrm{m}$; (C) other case of normal knee showing numerous and regularly distributed labeled cells in both the articular cartilage of the tibia (arrow) and in its growth plate (arrowhead). Bar, $50 \mu \mathrm{m}$; (D) another case with more irregular distribution of labeled cells (arrows) in the femur (top) and tibia (bottom). Bar, $25 \mu \mathrm{m}$. Legends: ac, articular cartilage; bm, bone marrow; fbm, bone marrow of the femur; fe, femur; me, meniscus; tbm, bone marrow of the tibia; ti, tibia. The dashes outline the bone shape.

\section{Knee Recovery and Regeneration after Injury}

In previous studies on limb regeneration in lizards [5,12,13,32], it was noted that the epiphysis of the proximal part of the tibia (Figure 3A), untouched by the amputation since the transection was made in the mid part of the hindlimb, showed a degeneration of most or part of the epiphyseal cartilage after 3-11 days from injury. This phenomenon was also seen for the proximal epiphysis of the femur, when the transection was made in the mid part of the thigh. In fact, cartilaginous cells of these not directly damaged epiphyses tend to loose the basophilic extracellular matrix, and they appear smaller or some apparently die following this un-direct wounding, a damage that also determines some necrosis in the bone and bone marrow (Figure 3B). The limb bone recovers and in the following 2-4 weeks numerous invading macrophages, osteoblasts and chondroblasts are formed in the healing area of the bone. Osteo-formative cells derive from the periosteum present near the amputation plane $[12,13,33]$. 
At about 30 days from the transection, the epiphyses contain new cartilaginous cells despite they were not hit by the injury (Figure 3C). Also the femur epiphysis, untouched from the amputation of half of the tibia and fibula, apparently reacts to the amputation stimulus with the production of new chondroblasts in the first $2-4$ weeks post-amputation.

This type of reactivity to a damage elicited in a distant region of the tibia or femur, was also noted for the inter-vertebral cartilages of the tail after amputation $[34,35]$. The proliferation of cartilaginous cells in the epiphyses is indicated from the presence of numerous 5BrdU-labeled cells in these regions (Figure 3D,E). This proliferative response suggests that lizard epiphyses and the periosteum have a broad regenerative potential, likely due to the permanence of a reserve of stem cells in these regions. These premises can explain the broad induction of cartilaginous tissue in the femur, tibia and fibula, after limb amputation followed by stimulation of the healing process using FGF1-2 ([26], this volume).
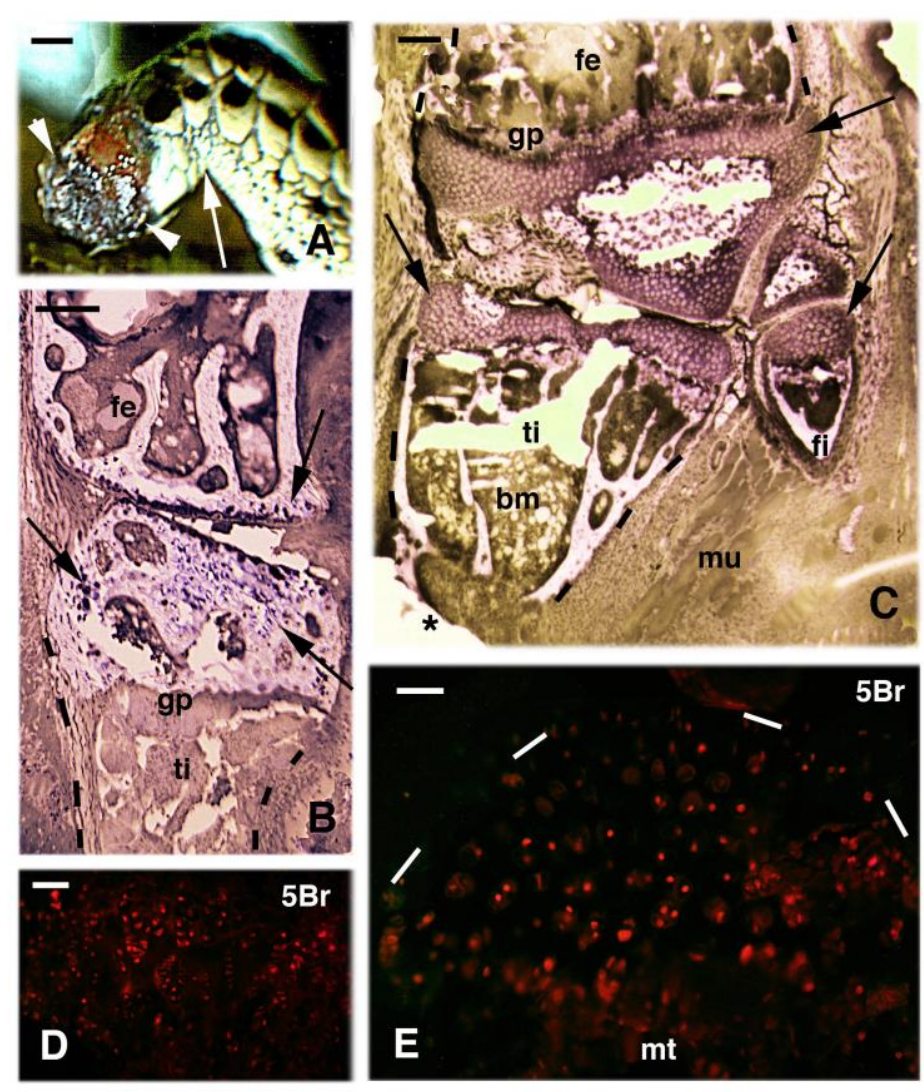

Figure 3. Images of amputated hindlimb (A), histological sections of the knee bones in the stump (B,C), and 5BrdU labeling (5Br, 4 hours post-injection) of regenerated cartilaginous epiphyses at about 30 days post-amputation (D,E) in P. muralis. (A) hindlimb stump (arrowheads indicate the stump surface) at 6 days post-amputation (the arrow indicate the knee). Bar, $1 \mathrm{~mm}$; (B) histological detail on the knee with untouched epiphyses, at 11 days post-amputation of the distal part of the limb. Arrows indicate that most cells of the cartilage have lost the extracellular, basophilic stain. Methyl-blue and Eosin stain. Bar, $100 \mu \mathrm{m}$; (C) knee bones of amputated hindlimb (the asterisks indicate the plane of cut) after about 25 days from the amputation. Large masses of cartilaginous tissues (arrows) are present in the epiphyses of femur (top), tibia and the smaller fibula (bottom). Bar, $50 \mu \mathrm{m}$; (D) detail on the 5BrdU-labeled cells $(5 \mathrm{Br})$ present in the growth plate located in a non-injured epiphysis at about 25 days post-amputation of the distal part of the femur. Bar, $20 \mu \mathrm{m}$; (E) 5BrdU-labeled cells in the cartilaginous epiphysis of an untouched femur at about 25 days post-amputation of the distal part of the limb. Bar, $20 \mu \mathrm{m}$. Legends: bm, bone marrow; fe, femur; gp, growth (metaphyseal) plate; mu, muscles; mt, metaphyseal (growth) plate; ti, tibia; The dashes outline the bone shape. 
In other experiments, after the damage of the epiphyses in the lizard P. muralis, by producing small cuts in the articular cartilage or in the diaphyses, the formation of irregular holes and cartilage degeneration occurs [34,36]. However, at 14, 21, 28 and 32 days post-injury, a variable amount of new cartilaginous tissue, sometimes mixed to fibrous connective, is observed in the epiphysis (Figure 4A-C). The new cartilaginous tissue is formed by small chondrocytes where few isogenous groups and relatively scarce cartilaginous matrix are present, as it is typical of an early forming cartilage (Figure 4C,D). The inter-cellular matrix increased among the chondrocytes at 32 days post-injury and later on, when a new mass of cartilaginous cells replaces the secondary centers of ossification in the epiphyses that were present before the injury. In the cases where experimental injury damaged also the periosteum of the diaphysis, a large cushion of cartilaginous tissues is formed after 3-4 weeks post-injury, that is located on the damaged side of the tibia (Figure 4A,B). This cartilaginous tissues shows a mix of hyaline and fibrous cartilage characteristics, and is continuous with the lamellar bone.

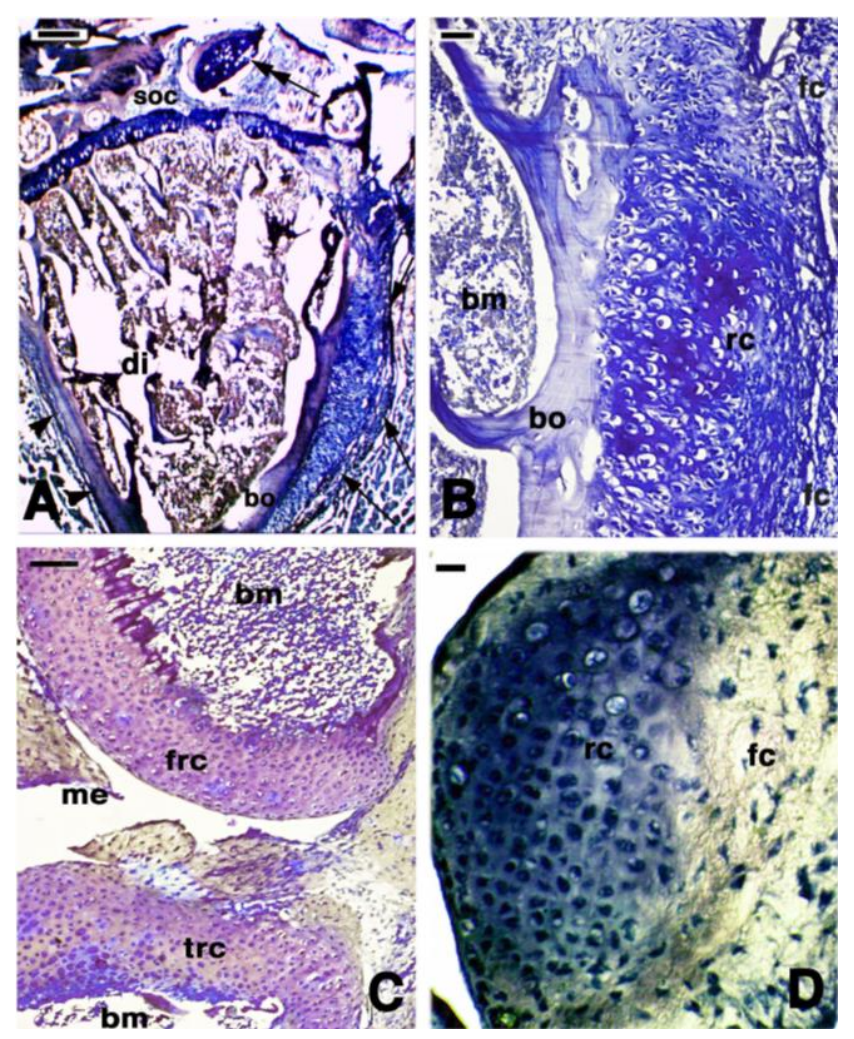

Figure 4. Cartilage regeneration after small injuries in the tibia $(\mathbf{A}, \mathbf{B})$ or knee $(\mathbf{C}, \mathbf{D})$ in $P$. muralis. (A-D, Methylene blue-Eosin stain). (A) the injury in the lateral periosteum located along the right diaphyseal bone has produced the formation of a cartilaginous tissue after 32 days (arrows). Also the articular cartilage has been injured by the surgical damage and a small cartilaginous nucleus is seen within the secondary ossification center (double arrow). The arrowheads point to the contralateral, untouched periosteum. Bar, $50 \mu \mathrm{m}$; (B) detail of the cartilaginous cushion formed between the diaphyseal bone and the external fibrous connective. Bar, $20 \mu \mathrm{m}$; (C) at 28 days post-injury of the knee, a large cartilaginous tissue replaces most of the secondary centers of the epiphyses. Bar, $50 \mu \mathrm{m}$; (D) detail on the numerous cells forming the regenerated cartilage originated inside the secondary ossification center (see position indicated by the double arrow in A). Bar, $20 \mu \mathrm{m}$. Legends: bm, bone marrow; bo, bone; di, diaphysis; fc, fibrous connective; frc, regenerated cartilage of the femur; me, meniscus; rc, regenerated cartilage; soc, secondary ossification center.

In the regenerating epiphyses at 21 and 32 days post-injury, 5BrdU-labeled cells are numerous not only in the superficial articular cartilage and growth plate but also in the inner mass of the 
epiphyseal cartilage, a different pattern from that of normal knees (Figure 5A,B). This observation indicates that chondroblasts are still actively multiplying within the new cartilage (interstitial growth). Immunohistochemistry for Chondroitin Sulfated Proteoglycan, collagen VI and Hyaluronate Receptor protein (Figure 5C-E) shows that these neo-formed chondrocytes actively produce these extracellular matrix components, suggesting that the large cartilaginous mass of the new epiphyses derives from an intense interstitial growth. Therefore, the regenerated cartilage at 14, 21 and 32 days post-injury shows numerous chondroblasts, as it is typical of younger epiphyseal cartilages (Figure 1B), and contains less extracellular matrix with respect to the older regenerated cartilage. It is likely that the regenerated cartilaginous epiphyses formed after knee injury, later mature into epiphyses with secondary centers, the initial condition present before injury in adult epiphyses $[31,32,34,36]$. This is also supported from the experiments using FGF1-2 that indicated at 50-70 days post-amputation of the limb, the beginning of formation of ossification centers in the induced cartilaginous anlagen of the tibia-fibula or of the femur ([26], this volume).

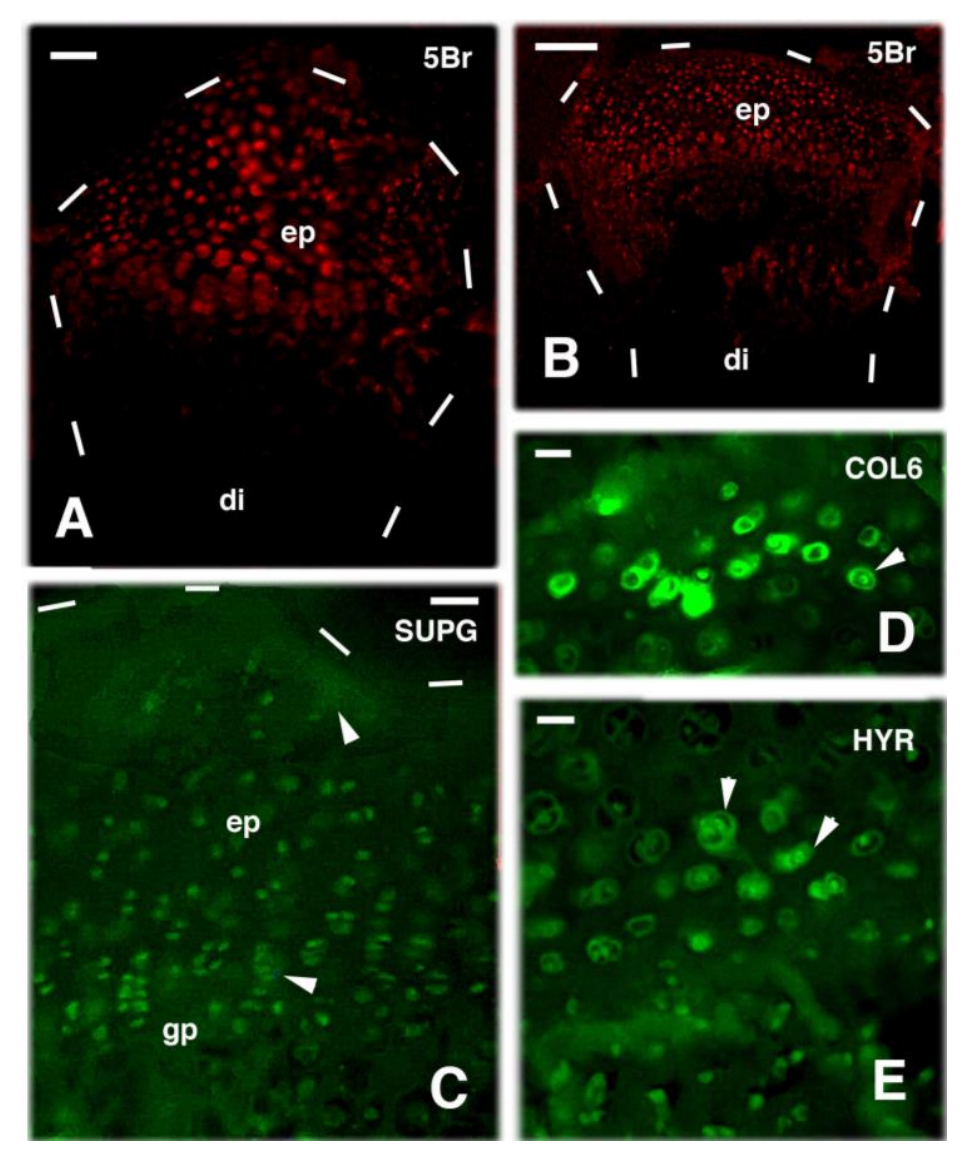

Figure 5. TRITC immunofluorescence after $4 \mathrm{~h}$ post-injection of 5BrdU (A,B) and FITC immunofluorescence for cartilaginous markers (C-E) in regenerating cartilages of the epiphyses in injured knees. (A) at 32 days post-injury, the regenerated epiphysis of a tibia shows numerous labeled cells $(5 \mathrm{Br})$. Bar, $20 \mu \mathrm{m}$; (B) at 32 days after injury the knee epiphysis is rich in labeled cartilaginous cells (5Br). Bar, $50 \mu \mathrm{m}$; (C) at 28 days post-injury the immunofluorescence for Condroitin Sulphate Proteoglycan, SUPG) is present in chondrocytes and weakly in the extracellular matrix (arrowheads) of the epiphysis. Bar, $20 \mu \mathrm{m}$; (D) immunofluorescence for collagen VI (COL6) is variable in regenerating chondrocytes but is intense in the ring-shaped pericellular matrix (arrowhead). Bar, $10 \mu \mathrm{m}$; (E) hyaluronate receptor immunolabeling (HYR) is detected in sparse chondrocytes and isogenous group, with the fluorescence concentrated intracellularly and in the pericellular region (arrowheads). Bar, $10 \mu \mathrm{m}$. Legends: di, diaphysis; ep, epiphysis; gp, growth plate (metaphyseal plate). Dashes outlined the shape of cartilages and bones. 
When large and multiple incisions are produced in the epiphyses of lizard knees and extensive damage is produced in the epiphyses, the strong inflammatory reaction determines a more limited production of cartilage that is mixed to a dense fibrotic connective.

\section{Knee Regeneration is Supported by Resident Progenitor Chondroblasts}

The epiphyses and the inter-vertebral cartilages of vertebrae in lizards retain a reserve of proliferating cells for bone growth, acting as growing centers [34,35]. This condition is a likely consequence of the process of morphogenesis of these bones that determines the localization of the stem cells in these growth centers. In mammalian growing long bones, proliferating chondroblasts remain initially localized prevalently on the articular surface [29] or in the articular surface and growth plates [28], like in lizard. Among the proliferating cells some cells that retain the 5BrdU-labeling may represent slow cycling cells, a characteristic of stem/primordial cells. The immunodetection of telomerase in some cells localized in the articular cartilage and growth plate further suggests that they are stem cells, destined to produce new cartilage [34] (Figure 6A-C). This enzyme, indicating a positive stimulator of numerous cell divisions, is also considered a marker for stem cells. Some studies have indicated that growth plates of adult lizards, although reduced to few cells and largely calcified toward the diaphysis, a typical aspect for close growth plates as seen in mammalian long bones (see [18,37]), can resume a proliferative activity during Spring-Summer when most somatic growth is re-activated in these reptiles [31,32]. In case of regenerating epiphyses after injury, telomerase positive cells are reduced or even disappear in the regenerated cartilage at 21 and 32 days post-injury. Rare and sparse cells remain localized at the base of the cartilage confining with the diaphysis, the growth plate (Figure 6D). Although it is likely, we do not have a direct proof that also primordial/stem cells present in the bone marrow can participate to the differentiation into chondrocytes after bone fracture or damage. In mammalian bones, marrow cells form bone tissue but little or no cartilage [19,20,37]. In lizards, frogs and salamanders, the injured periosteum has a broad chondrogenic potential [11,15,21,22], and this enhanced chondrogenesis may be related to the mechanical stimulus derived from the free movement of the fractured lizard bones in the injured areas of bone since no containment or ligature of the injured bones was made. The large mass of cartilaginous cells (callus) that is formed after bone fracture in both frog and lizard is later replaced by new bone through a process of endochondral ossification [11]. However even in urodeles, amphibians that are able to regenerate the entire limb, the removal of large part of the diaphysis (where no or few proliferating cells are present) often determines lack of regeneration of the diaphysis, a strange results that remains to be explained [21,22,38].

The above examples of cartilage regeneration in the long bones and knees of lizards indicate that the permanence of putative stem/primordial cells in the epiphyses is a pre-adaptation for cartilage regeneration in adults after injury. While in most mammals somatic growth slows down or ceases after sexual maturity, in amphibians and reptiles somatic growth lasts for most of their lifetime, although it is variably reduced in mature or in old adults. The growing centers of these reptiles, located in the growth plates, remain active or can resume proliferation in Spring-Summer or after injury, providing inflammation is not extensive, otherwise they tend to form an irregular scarring connective tissue. Lizard perichondrium in both vertebrae and knees also appears sensitive to diffusible signals derived from the lesion or amputation of nearby tissues, and it seems to react by chondroblasts proliferation. The latter can be stimulated by the administration of growth factors that favor the regeneration of a cartilaginous anlage of the femur, tibia and fibula, as it has been shown by treating regenerating lizard limbs with FGF1-2 ([26], this volume). The potential of cartilage regeneration in lizards, and perhaps in other ectothermic reptiles, appears higher than in mammals and birds where instead a fibrous connective tissue is formed after injury. However, in both lizards and amphibians the damage has to be limited in order to avoid a strong process of inflammation, otherwise cartilage regeneration is impaired and a dense fibrous connective tissue is produced in different proportions with respect the cartilage, resembling the fibrotic process typical for mammals. It is likely that the inflammatory and immune reactions to injury, stronger in mammals than in ectothermic vertebrates, participate in 
limiting the regeneration of their injured tissues [23-25], including the cartilage [39]. Further study on inflammation and chondrogenesis in lizard is required.

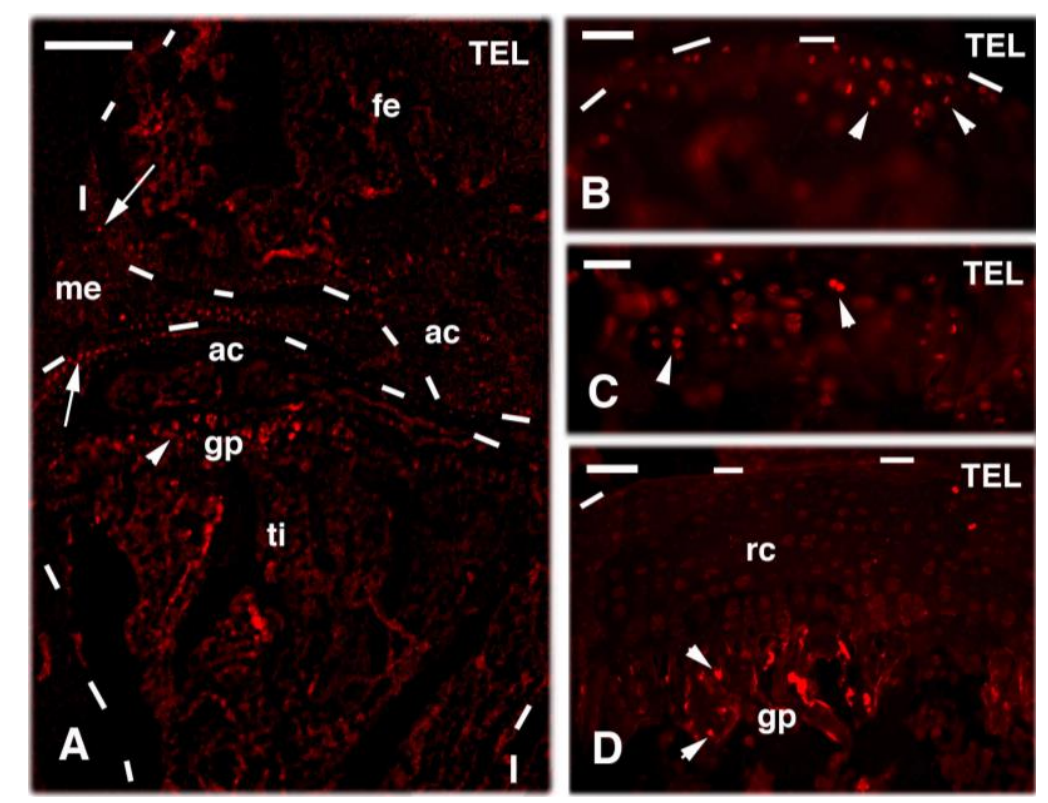

Figure 6. Telomerase immunolocalization in normal (A-C) and 28 days regenerated (D) knee epiphyses. (A) few cells appear labeled in the articular cartilage (arrows) and growth plate (arrowheads). Bar, $50 \mu \mathrm{m}$; (B) detail on labeled cells (arrowheads) present in the articular cartilage of a normal femur. Bar, $20 \mu \mathrm{m}$; (C) other detail showing few labeled cells (arrowheads) located in the growth (metaphyseal) plate of the femur. Bar, $20 \mu \mathrm{m}$; (D) few labeled cells are still visible in the growth plate (arrowheads) while the remaining regenerated cartilage is almost devoid of labeled cells. Bar, $20 \mu \mathrm{m}$. Legends: ac, articular cartilage; fe, femur; gp, growth plate; me, meniscus; rc, regenerated cartilage of the epiphysis. ti, tibia. Dashes outlined the shape of cartilages and bones.

Acknowledgments: The present material and laboratory analysis was carried on mainly supported by Comparative Histolab, Padova, Italy. No funds were received from UNIBO.

Conflicts of Interest: The author declare no conflict of interest.

\section{References}

1. Bellairs, A.d'A.; Bryant, S.V. Autotomy and Regeneration in Reptiles. In Biology of the Reptilia; Gans, C., Billet, F., Maderson, P.F.A., Eds.; John Wiley \& Sons: Hoboken, NJ, USA, 1985; Volume 15B, pp. 302-410.

2. Alibardi, L.; Sala, M. Indagini istochimiche sulla struttura della cartilagine rigenerata nella coda di Lacerta sicula. Arch. Ital. Anat. Embr. 1981, 88, 163-182.

3. Alibardi, L.; Meyer-Rochow, V.B. Comparative fine structure of the axial skeleton inside the regenerated tail of lizards and the tuatara (Sphenodon punctatus). Gegenbaurs Morphol. Jahrb. 1989, 135, 705-716. [PubMed]

4. Alibardi, L. Development of the axial cartilaginous skeleton in the regenerating tail of lizards. Bull. Assoc. Anat. 1995, 79, 3-9.

5. Alibardi, L. Morphological and cellular aspects of tail and limb regeneration in lizard: A model system with implications for tissue regeneration in mammals. Adv. Anat. Embryol. Cell Biol. 2010, 207, 1-112.

6. Alibardi, L. Original and regenerating lizard tail cartilage contain putative resident stem/progenitor cells. Micron 2015, 78, 10-18. [CrossRef] [PubMed]

7. Fisher, R.E.; Geiger, L.A.; Stroik, L.K.; Hutchins, E.D.; George, R.M.; DeNardo, D.F.; Kosumi, K.; Rawls, J.A.; Wilson-Rawls, J. A histological comparison of the original and regenerated tail in the green anole, Anolis carolinensis. Anat. Rec. 2012, 295, 1609-1619. [CrossRef] [PubMed] 
8. Gilbert, E.A.B.; Payne, S.L.; Vickaryous, M.K. The anatomy and histology of caudal autotomy and regeneration in lizards. Physiol. Biochem. Zool. 2013, 86, 631-644. [CrossRef] [PubMed]

9. Lozito, T.P.; Tuan, R.S. Lizard tail regeneration: Regulation of two distinct cartilage regions by Indian hedgehog. Dev. Biol. 2015, 399, 249-262. [CrossRef] [PubMed]

10. Lozito, T.P.; Tuan, R.S. Lizard tail skeletal regeneration combines aspects of fracture healing and blastema-based regeneration. Development 2016, 143, 2946-2957. [CrossRef] [PubMed]

11. Pritchard, J.J.; Ruzicka, A.J. Comparison of fracture repair in the frog, lizard and rat. J. Anat. 1950, 84, 236-262. [PubMed]

12. Alibardi, L. Cell proliferation in the amputated limb of lizard leading to scarring is reduced compared to the regenerating tail. Acta Zool. 2017, 98, 170-180. [CrossRef]

13. Alibardi, L. Immunolocalization of 5BrdU long retaining labeled cells and macrophage infiltration in the scarring limb of lizard after limb amputation. Tiss. Cell 2016, 48, 197-207. [CrossRef] [PubMed]

14. Lozito, T.P.; Tuan, R.S. Lizard tail regeneration as an instructive model of enchanced healing capabilities in an adult amniote. Conn. Tiss. Res. 2016, 26, 1-10.

15. Neufield, D.A. Bone healing after amputation of mouse digits and newt limbs: Implications for induced regeneration in mammals. Anat. Rec. 1985, 211, 156-165. [CrossRef] [PubMed]

16. Stocum, D.L. Regenerative Biology and Medicine; Academic Press-Elsevier: London, UK, 2006.

17. Han, M.; Yang, X.; Taylor, G.; Bursdal, C.A.; Anderson, R.A.; Muneoka, K. Limb regeneration in higher vertebrates: Developing a roadmap. Anat. Rec. 2005, 287B, 14-24. [CrossRef] [PubMed]

18. Hunziker, E.B.; Kapfinger, E.; Geiss, J. The structural architecture of adult mammalian articular cartilage evolves by a synchronized process of tissue resorption and neoformation during postnatal development. Osteoarthr. Cartil. 2007, 15, 403-413. [CrossRef] [PubMed]

19. Colnot, C. Skeletal cell fate decisions within periosteum and bone marrow during bone regeneration. J. Bone Min. Res. 2009, 24, 274-282. [CrossRef] [PubMed]

20. Egawa, S.; Miura, S.; Yokoyama, H.; Endo, T.; Tanura, K. Growth and differentiation of a long bone in limb development, repair and regeneration. Dev. Growth Differ. 2014, 56, 410-424. [CrossRef] [PubMed]

21. Cosden, R.S.; Lattermann, C.; Romine, S.; Gao, J.; Voss, S.R.; MacLeod, J.N. Intrinsic repair of full-thickness articular cartilage defects in the axolotl salamander. Osteoarthr. Cartil. 2011, 19, 200-205. [CrossRef] [PubMed]

22. Lee, J.; Gardiner, D.M. Regeneration of limb joints in the axolotl (Ambystoma mexicanum). PLoS ONE 2012, 7, e50615. [CrossRef] [PubMed]

23. Mescher, A.L.; Neff, A.W.; King, M.W. Inflammation and immunity in organ regeneration. Dev. Comp. Immunol. 2017, 66, 98-110. [CrossRef] [PubMed]

24. Godwin, J.W.; Rhosenthal, N. Scar-free healing and regeneration in amphibians: Immunological influence on regenerative success. Differentiation 2014, 87, 66-75. [CrossRef] [PubMed]

25. Alibardi, L. Microscopic observations show invasion of inflammatory cells in the limb blastema and epidermis in pre-metamorphic frog tadpoles which destroy the apical epidermal cap and impede regeneration. Ann. Anat. 2016, 210, 94-102. [CrossRef] [PubMed]

26. Alibardi, L. FGFs treatment on amputated lizard limbs stimulate the regeneration of long bones, opening new avenues for limb regeneration in amniotes. J. Funct. Morphol. Kinesiol. 2017, under review.

27. Alibardi, L. Permanence of proliferating cells in developing, juvenile and adult knee epiphyses of lizards in relation to bone growth and regeneration. Acta Zool. 2017, 98, 278-284. [CrossRef]

28. Mankin, H.J. Localization of tritiated thymidine in articular cartilage of rabbits: I. Growth in immature cartilage. J. Bone Joint. Surg. 1962, 44, 682-688. [CrossRef]

29. Archer, C.W.; Morrison, H.; Pitsillides, A.A. Cellular aspects of the development of diarthrodial joints and articular cartilage. J. Anat. 2009, 184, 447-456.

30. Reno, P.L.; McBurney, D.L.; Lovejoy, C.O.; Horton, W.E. Ossification of the mouse metatarsal: Differentiation and proliferation in the presence/absence of a defined growth plate. Anat. Rec. 2006, 288A, 104-118. [CrossRef] [PubMed]

31. Haines, R.W. The evolution of epiphyses and of endochondral bone. Biol. Rev. 1942, 17, 267-292. [CrossRef]

32. Haines, R.W. Epiphyses and Sesamoids. In Biology of the Reptilia; Gans, C., Ed.; Academic Press: London, UK, 1969; Volume 1 Morphology A, pp. 81-115.

33. Alibardi, L. Ultrastructural features of the process of wound healing after tail and limb amputation in lizard. Acta Zool. 2010, 91, 306-318. [CrossRef] 
34. Alibardi, L. Regeneration of the articular cartilage in lizard knee from resident stem/progenitor cells. Int. J. Mol. Sci. 2015, 16, 20731-20747. [CrossRef] [PubMed]

35. Alibardi, L. Localization of proliferating cells in the inter-vertebral region of the developing and adult vertebrae of lizards in relation to growth and regeneration. Anat. Rec. 2016, 299, 461-473. [CrossRef] [PubMed]

36. Alibardi, L. Regeneration of the epiphyses including the articular cartilage in the injured knees of the lizard Podarcis muralis. J. Dev. Biol. 2015, 3, 71-89. [CrossRef]

37. Shapiro, F. Bone development and its relation to fracture repair. The role of mesenchymal osteoblasts and surface osteoblasts. Eur. Cells Mater. 2008, 15, 53-76. [CrossRef]

38. Hutchinson, C.; Pilote, M.; Roy, S. The axolotl limb: A model for bone development, regeneration and fracture healing. Bone 2007, 40, 45-56. [CrossRef] [PubMed]

39. King, M.W.; Neff, A.W.; Mescher, A.L. The developing Xenopus limb as a model for studies on the balance between inflammation and regeneration. Anat. Rec. 2012, 295B, 1552-1561. [CrossRef] [PubMed]

(C) 2017 by the author. Licensee MDPI, Basel, Switzerland. This article is an open access article distributed under the terms and conditions of the Creative Commons Attribution (CC BY) license (http://creativecommons.org/licenses/by/4.0/). 